\title{
Attenuation of Avoidance Coping and Enhancing Approach Coping Strategies of Adolescent Girls
}

\author{
Dr. Priyanka A. Rao ${ }^{1 *}$
}

\section{ABSTRACT}

The objective of present study is to asses and enhances the coping strategies of adolescent girls. Adolescent defined as stage of storm and stress along with at this age proper training for adoptive coping skills would result for mentally healthy individual further family and society. Coping is individual capacity to deal as well manage with various stress of life without causing greater loss or getting back to homeostatic phase again. Coping is mainly of two type functional and dysfunctional coping or problem focused and emotional focused. Functional coping strategies are contributing factor and dysfunctional are threats to mental health. Purpose of this study was to enhance functional coping strategies in adolescent's girls and lessen the use of dysfunctional coping skill. Sample for present study consist of 120 adolescents girls those who were having several issue. By giving them training of behavioral technique, meditation and relaxation, technique for the period of three months we assessed their coping strategy. Coping strategies scale by Srivastava used to measure the coping of girls before and after giving the training for approx three months.

The result shows significant difference between the score on coping strategy scale before and after the training. Functional coping skills enhanced and use of dysfunctional coping lessened. To observe the mean difference t test carried out to see the pre to post test difference. Findings suggest that Meditation, Behavioral techniques and Muscles relaxation Technique was considerable impact on enhancing functional coping skill as well as reducing avoidance coping.

Keywords: Coping, Adolescent, Progressive Muscles relaxation, Meditation, Gender.

The word coping is frequently used to describe ways of dealing with stress or to modify or elevate the conditions causing harm, threat or challenge. Adolescents are a stage of various stressors defined as storm, confusion and most difficult transformational phase. These changes can seen in form of physical, emotional, psychological as well as cognitive and social form, most

\footnotetext{
${ }^{1}$ Ph.D, Department of Psychology, University of Delhi, Delhi

*Responding Author

(C) 2016 I P Rao; licensee IJIP. This is an Open Access Research distributed under the terms of the Creative Commons Attribution License (http://creativecommons.org/licenses/by/2.0), which permits unrestricted use, distribution, and reproduction in any Medium, provided the original work is properly cited.
} 


\section{Attenuation of Avoidance Coping and Enhancing Approach Coping Strategies of Adolescent Girls}

of the time these changes are described in negative way. More often than not adolescents misunderstood by others during the process of becoming adult and leaving behind their childhood. This phase is characterized by state of confusion regarding their role and identity, being rebellious, deviance from social norms, sibling rivalry, peer pressure, depression, anger, issues of sexuality, energetic and trying to fit in particular identity moreover identity formation is also dominant in this developmental stage of human. Adolescent youth experiences enormous and sudden changes in every aspect of their life, as neither they expected to behave like a kid nor given rights like an adult as they make transition from childhood to adulthood thus proper and functional coping skills became very crucial to develop a healthy adolescent. This age characterized by energy, emotional vicissitudes and various other changes. Gender is one important aspect of adolescent as experience of being adolescent girl is entirely different from experiencing being an adolescent boy. Further due to our social and cultural limitation as well as restriction girls may face more severe symptoms of developing as adolescent. As in a longitudinal research, it has shown that feelings of self-esteem tend to decrease somewhat as girls become adolescents, with different patterns emerging for different ethnic groups (Brown et al., 1998). Particularly in early adolescence, some studies have shown that boys tend to have higher global self-esteem than girls do (Bolognini, Plancherel, Bettschart, \& Halfon, 1996; Chubb, Fertman, \& Ross, 1997).

As present study address, only adolescent girls for enhancing their functional coping skills via various methods let us discuss issues specific to girl development as an adolescent. Moreover Gender identity refers to whether people consider themselves to be primarily masculine, primarily feminine, or some combination of the two. During early to mid-adolescence, youths' understanding of gender is quite rigid and stereotyped. As a result, younger adolescents will typically participate in more gender-stereotyped behaviors than do older adolescents will. By late adolescence, youth have usually figured out their role in society, including their gender role, and they have established a secure and comfortable individual identity that corresponds to their values, beliefs, and interests. youth begin to enjoy in late adolescence is indicative of a more mature understanding of gender; one that recognizes gender is best understood along a continuum, ranging from purely masculine to purely feminine, with most people falling somewhere in between these two extreme pole (Angela Oswalt, 2010).

As described above process of identity formation and development is not prevalent in our society as growing girls are subject to limitation such as exposure to outer world, fixed way of talking, laughing, walking etc. Culture treats the female body as a sexual object thus girls and women learn to view their own bodies as objects, focusing on how the body appears rather than how it feels. This internalization of their physical self results in shame, guilt and decreases self awareness, peak motivational states and diminished awareness of internal body states. Thus they rarely get chance to grow an established an individual identity even female children do not have the opportunity to feel safe, lovable, accepted, and worthy (Miller 1981). Therefore, these additional factors make girls more vulnerable to usage of dysfunctional coping skills which 
further leads to poor mental health. Feminine identity in itself defined as being submissive, emotional and other behavior, which is in the line with dysfunctional coping strategies. Hence, present research is focusing on enhancing the functional coping strategies as well as lessening the usage of avoidance dysfunctional coping strategies of adolescent girls via training cognitive behavioral methods, Meditation and Progressive Muscles relaxation.

Coping responses can be active in nature and oriented towards confronting a problem, or they can be strategies that entail an effort to reduce tension by avoiding dealing with a problem.

\section{Approach/ Functional coping style:}

Functional coping skills involves facing the realities of issue consciously and taking some concrete action to solve the problem at the individual level or with the help of other people these style of coping with issues are functional. This also resembles as approach coping, encompasses actions such as planning, strategizing, and applying effort that aim to correct the situation rather than passively allowing the stressor to continue (Skinner et al., 2003). Approach coping also includes emotion-focused strategies such as emotion regulation and cognitive restructuring (Carver \& Connor-Smith, 2010; Cronkite \& Moos, 1995; Moos \& Schaefer, 1993). Further approach coping can be viewed in following categories.

1. Behavioral approach coping consists of the conscious use of an obvious action in response to stressful appraisal of a situation or event when individual confronts the stressor (Krohne, 1993), it may include enhancing one's effort to resolve the issue and identifying the source of stress to prevent its reoccurrence .

2. Cognitive approach coping skills includes strategies such as logical analysis, mental rehearsal of problem resolution, and restructuring cognitions to find positives from the experience. Cognitive approach coping consists of a conscious thought or emotion in which the individual is "oriented toward the threat-related aspects of a situation" (Krohne, 1993).

\section{Avoidance style/Dysfunctional coping style:}

On the other hand ,the second category consists of a person who decide to suffer from ,accept or deny the experienced stress /problem or issues or put blame on somebody (self or other) for being in that situation.

Behavioral avoidance coping is characterized by engaging in behaviors aimed to reduce negative effect in response to the stressor. These strategies include behaviors such as substance use and seeking new activities to find sources of relief or satisfaction. Behavioral avoidance coping is the conscious decision to physically remove oneself from a threatening environment. Examples are walking away from the stress source or avoiding a threatening or unpleasant situation. 
Cognitive avoidance characterized by denial of the crisis or "deciding that the basic circumstances cannot be altered” (Moos \& Schaefer, 1993). Cognitive avoidance coping reflects, “Turning away from threatening cues” (Krohne, 1993) for example, filtration of information, selective attention, and distraction.

There are seven styles of coping that are used -

- Blaming on others

- Avoiding the stressors

- Asking others for the help

- Engaging in indirect stress reducing activities

- Collecting information

- Acting opposite of the way one feels

- Minimizing the importance of issue

- Social \& emotional support from others helps in coping.

\section{Enhancing coping skills/ capabilities:}

There are several ways to enhances coping strategies of adolescent girls such as Exercise , Practicing yoga, indulging in recreational activities, adequate communication skills, building relationships and peer counseling activities, Changing gears : It involves shifting from issue to something else for e.g., Activities that capture one’s interest, Pamper yourself, Warm-up slowly etc.

In the present study following three methods used for the purpose of enhancing approach coping strategies and lessening the usage of avoidance coping for the adolescent girls. These were following:

\section{Interventions:}

Stress is an unpleasant fact. Stressors are all around us at work, in our environment, and in our personal lives. Adolescence is a particularly stressful period in life. High levels of psychological stress can found in almost one third of adolescents (Cunningham, Brandon, \& Frydenberg, 2002). This may be a result of having to deal with a variety of stressful events at the same time using a limited set of coping skills (Seiffge-Krenke, Weidemann, Fentner, Aegenheister, \& Poeblau, 2001). We can divide coping technique in following categories: physiological, cognitive, and behavioral.

\section{Physiological coping skills:}

Common physiological responses to stress include tense muscles, racing pulse, pounding heart, dry mouth, queasy stomach, and sweating. However, several coping techniques can be effective. One of the most effective procedures is learning to reduce the tension in our own muscles through progressive relaxation. In progressive relaxation, we learn to relax by alternately flexing and relaxing, one by one, muscle groups throughout the body. To use this technique, begin by 
alternately flexing and relaxing muscles to appreciate the difference between relaxed and tense muscles. Next, you might shake your shoulders by slowly rolling them up and down. Now relax your neck. Systematically, extend this process until your body is completely relaxed from head to toe. Controlled breathing is also important. When we are tense, we tend to take in relatively short, shallow breaths. However, as your body slows down during relaxation, notice that our breathing change to deeper, longer breaths. Relaxation procedures are effective in reducing emotional as well as physical tension.

Another technique, which used in this project, is Meditation, which is often effective for achieving a relaxed state.

\section{Behavioral coping technique:}

Behavior is that part of human existence that communicate to others how a person feels, what a person thinks, and who a person is behavior is a tool or means by which people accomplish, perform, or in other ways achieve that which, they set as their goals. Behavior can be the cause of a person's failures, mistakes, or disappointments. Because behavior is the outward manifestation of a person's inner self, it may sometimes seem to be unconnected to him or her. Whatever the case many clients' problem involves some manifestation of behavior? And oftentimes, the best approach to working with client problems is by addressing behavioral changes. The overall goal of behavioral interventions is to help clients develop adaptive and supportive behaviors to multifaceted situations. Developing adaptive behavior often involves weakening or eliminating behaviors that work against the desired outcomes, acquiring or strengthening desirable behaviors, or both. Behavioral interventions used in this project are Role play and Role rehearsal, self management, self monitoring, and self reward. A basic behavioral skill involves defining behaviors: helping the client understand the complexity of behavioral tasks; breaking tasks down into sequential behaviors.

Whereas in a study with inpatient adolescents between 12 and 16 years examining gender differences in coping strategies, female adolescents were more likely to engage in avoidance coping and interpersonal coping strategies, while male adolescents were more likely to engage in physical activities (Recklitis \& Noam,1999 ).

Female adolescents tended to endorse engaging in seeking social support, wishful thinking, and tension reduction more frequently than did male adolescents (Frydenberg \& Lewis, 1993a).

Female adolescents were more likely to seek social support and less professional help, as well as engage in tension reduction, self-blame, worry, and report less ability to cope than did male adolescents (Frydenberg \& Lewis, 2000). 


\section{Hypothesis:}

1. There will be an increase in approach coping strategies for the adolescents participating in intervention program from pre to post treatment. This improvement will be greater for the various treatment groups than control group (who are remaining constant from pre to post treatment testing).

2. There will be decrease in usage of avoidance coping strategies in the adolescents who are participating in various intervention programs from pre to post treatment. This decrease in using avoidance coping will be greater for the treatment group compared to the control group.

\section{METHODOLOGY:}

\section{Rationale:}

As present study is focused on issue of adolescent girls, there are several emerging developmental issue, role conflict in different situation etc that needed to be deal effectively. When there is family/social/friends support one can cope effectively with these issues however when unable to with these issue in adaptive manner several physical \& psychological problem arises such as stress, low self-esteem. Therefore, by making girls aware about functional coping skills we can promote their mental health and wellness.

Participants for this study are adolescent girls from class eighth and ninth, recruited from a government school belonging to average age group of 13 to 16 years. Total sample size is 120 girls further assigned in various groups as control group, treatment group 1, 2 and 3.

Treatment group no. 1 characterized by introduction of behavioral intervention as role-play \& role rehearsal, behavior modification, goal setting self management, self monitoring, and self reward and Contracting: Helping the client establish commitments, time lines, and record keeping for change (A diary was maintained by each student for record keeping).

Treatment group No.2 distinguished by practicing progressive muscles relaxation techniques. Treatment group no.3 was introduced meditation.

Whole intervention program carried out approx three months including introduction and preparation. Student with severe behavioral and emotional problems as well as physical health issue were not included in the study. Student information blank filled up by the student and permission for participation in the study received from parent/guardians.

Only girls selected for the purpose of maintenance of homogeneity of group. Equivalence of the group established by administering coping strategies scale further applying ANOVA to see that groups are not significantly different on various dimension of approach and avoidance coping strategies scales (table 1.1). 
As discussed above Coping is measure by coping strategic scale of A.K. Srivastava. Moreover Coping word used to describe ways of dealing with stress or to modify or elevate the conditions causing harm, threat or challenge. This scale measures Behavioral approach, cognitive approach, cognitive behavioral approach, behavioral avoidance and cognitive avoidance coping strategies as well consist of 50 items.

\section{Objectives:}

- For enhancing functional coping skills and make them aware about dysfunctional coping skills.

- To eliminate and prevent inner conflicts

- To understand herself and accept herself as they are.

Experimental Design of Study:

\begin{tabular}{|l|l|l|l|l|l|l|l|l|}
\hline Variables & \multicolumn{2}{|l|}{ Pre test } & \multicolumn{3}{l|}{ Post test } & T3 \\
\hline Coping & Control & T1 & T2 & T3 & Control & T1 & T2 & T3 \\
\hline $\begin{array}{l}\text { Approach } \\
\text { Coping }\end{array}$ & $\mathrm{N}=30$ & $\mathrm{~N}=30$ & $\mathrm{~N}=30$ & $\mathrm{~N}=30$ & & & & \\
\hline $\begin{array}{l}\text { Avoidance } \\
\text { Coping }\end{array}$ & & & & & & & & \\
\hline
\end{tabular}

$\mathrm{N}=120$

Both control group and before after experimental design used.

\section{RESULT AND DISCUSSION:}

The purpose of the study is to determine if there is any difference among the group where various treatment introduced and those who are not given any treatment the on the coping strategies of adolescent girls. Both the control group and experimental groups were administered the coping strategies scale by A.K. Srivastava, to establish the baseline. Further groups mentioned as control group, where no treatment introduced, T1, where only cognitive behavioral techniques introduced, T2 where Progressive Muscles relaxation practiced and for the group T3 meditation implied for the three months.

Analysis of variance (Table 1) shows that there is no significant difference among groups of adolescent girls before giving the treatment. Accordingly, result clearly indicates that there is no significant difference between control group and various treatment groups on the dimension of coping strategies. After treatment, introduce to the group, again analysis of variance carried out to observe the significance of difference among groups (Table 2). Moreover paired t test was also applied to observe the significant of difference for approach coping and avoidance coping, before and after the introducing all three treatment group.

As present study assumed that intervention would produce an increase in approach coping for the girls who are participating in intervention program from pre to post treatment, is accepted. As findings, suggest that there is enhancement of approach coping due to practicing self-monitoring, 


\section{Attenuation of Avoidance Coping and Enhancing Approach Coping Strategies of Adolescent Girls}

self-management, role-play and rehearsal, mediation and progressive muscles relaxation techniques.

The results presented (Table 2) indicates that there is significant difference among control group and group who practiced behavioral techniques. It can be infer that due to practicing various behavioral techniques such as role-play, role rehearsal, self-management etc are helpful in enhancing approach coping strategies. Due to role-play and role rehearsal one get chance to understand the perspective of other person involved in interaction as well, provide an opportunity to develop capacity to managing responses in adoptive way. By observing the difference on avoidance, it is reveals that control group and the group who received training for behavioral intervention significantly differs from each other, shows the effect of treatment for lessening the usage of avoidance coping. These patterns of coping found to have produced negative impact on well being in long term thus it becomes very crucial to provide training to lessen these in life of adolescents' girls for their overall development as fully functioning individual. In another study, also behavioral techniques were significantly high of effectiveness in compared to nonbehavioral coping strategies (Durlak \& Wells, 1997). Although comparing the effectiveness of various treatments is not here concerned, thus comparison made only between control and treatment group as well as pre to post differences.

Further observing the results of practice of progressive muscles, relaxation it can suggested that it has significantly enhanced the approach coping (table 3) and lessen the avoidance coping ( table 4) among adolescent girls. Studies had reported those adolescents are more prone to use dysfunctional coping furthermore accepting responsibility and escape avoidance coping were high among girls (Dubat, Punia \& Goyal,1997). Relaxation technique can be very useful in dealing with stressors by accepting themselves, role confusion and bodily changes, studies has established the efficacy of Progressive muscle relaxation on regulation of blood pressure, heart rate and other physiological changes for female adolescents (Nickel etal. ,2005). Moreover, relaxation also produces positive outcome as improve sleep, decreased pain, and perceived stress and anxiety (McCallie \& Blum, 2006; Parlow \& Jones, 2002). Thus, it's advocated that training of PMR will induce healthy coping habits among adolescent girls. Moreover, efficacy of this particular method over other methods or in combination with other techniques can studied extensively in future research for the adolescent groups.

Effect of Meditation extensively studied in various age groups while for the adolescent it is not popular (Ospina et al., 2007 ) hence present study has tried to see the worth of meditation for adolescent girls by comparing control group as well as pre to post test analysis. Moreover findings suggest that it's a effective technique to resolve the conflict emerging due to development changes and prepare adolescent girls to accept themselves as they are further enhances positive feelings and courage to face the challenges instead of avoiding them to face. Meditation may improve cognitive abilities of adolescent students as similar results was found in 
school based meditation program that it enhanced ability to pay attention, improved concentration, and decreased anxiety (Beauchemin et al., 2008).

From the above findings, it can concluded that for functional or adoptive coping with various adolescents phase crises proper training can be intervened through behavioral techniques, practicing meditation and relaxation techniques for adolescent girls. Female adolescent are more vulnerable to stress as well as high on usage of dysfunctional coping that leads to depression. Further, Nolen-Hoeksema (1994) has suggested that one factor contributing to adolescent girls' .increased vulnerability to depression is how they cope with stress. It may be that girls and boys tend to cope differently, and that the girls' coping styles place them more at risk for experiencing depression. Above coping techniques, allow one to be more aware of their own physical and emotional state. Therefore, we can conclude that training of behavioral techniques, meditation as well as progressive muscles relaxation improves the efficiency of adolescent girls for resolving the stress by concrete actions, planning and confrontation further decrease the usage of avoidance means toward stressors of life.

Table 1: One-Way Analysis Of Mean Differences For Groups Of Adolescent Girls Before The Intervention-

\begin{tabular}{|l|l|l|l|l|l|l|l|}
\hline & $\begin{array}{l}\text { Sum of } \\
\text { Squares }\end{array}$ & & Df & $\begin{array}{l}\text { Mean } \\
\text { Square }\end{array}$ & F & Sig. & \\
\hline $\begin{array}{l}\text { Approach } \\
\text { Coping }\end{array}$ & $\mathbf{3 1 0 . 1 5 8}$ & & 3 & 103.388 & 1.97 & NS & \\
\hline $\begin{array}{l}\text { Avoidance } \\
\text { Coping }\end{array}$ & $\mathbf{2 1 5 . 0 3 3}$ & & 3 & $\mathbf{7 1 . 6 7 8}$ & $\mathbf{. 8 6}$ & NS & \\
\hline
\end{tabular}

Table 2: One-Way Analysis Of Mean Differences For Groups Of Adolescent Girls After The Intervention-

\begin{tabular}{|l|l|l|l|l|l|l|l|}
\hline & $\begin{array}{l}\text { Sum of } \\
\text { Squares }\end{array}$ & & Df & $\begin{array}{l}\text { Mean } \\
\text { Square }\end{array}$ & F & Sig. & \\
\hline $\begin{array}{l}\text { Approach } \\
\text { Coping }\end{array}$ & $\mathbf{8 4 5 1 . 4 9}$ & & 3 & 2817.16 & $31.223 * *$ & S & \\
\hline $\begin{array}{l}\text { Avoidance } \\
\text { Coping }\end{array}$ & $\mathbf{8 9 2 4 . 0 3 3}$ & & 3 & $\mathbf{2 9 7 4 . 6 7}$ & $34.542 * *$ & S & \\
\hline
\end{tabular}

** $\mathbf{p}>\mathbf{0 . 0 1}$

Table 3: Pre To Post Treatment Mean Difference On Approach Coping -

\begin{tabular}{|c|c|c|c|c|c|}
\hline \multirow[t]{2}{*}{ Groups } & \multicolumn{2}{|c|}{ Mean } & \multirow[t]{2}{*}{$\mathbf{T}$} & \multirow[t]{2}{*}{ Df } & \multirow[t]{2}{*}{ Sig. } \\
\hline & Pre & Post & & & \\
\hline Control & 57 & 56 & 1.479 & 29 & N.S \\
\hline Treatment 1 & 54 & 66 & -5.93 & 29 & $\mathrm{~S}$ \\
\hline Treatment 2 & 53 & 73 & -8.72 & 29 & $\mathrm{~S}$ \\
\hline Treatment 3 & 55 & 78 & -11.54 & 29 & $\mathrm{~S}$ \\
\hline
\end{tabular}


Table 4: Paired sample t test for the groups of adolescent girls on avoidance coping-

\begin{tabular}{|l|l|l|l|l|l|}
\hline Groups & Mean & T & Df & Sig. \\
\hline & Pre & Post & & & \\
\hline Control & 57 & 56 & 1.479 & 29 & N.S \\
\hline Treatment 1 & 54 & 66 & -5.93 & 29 & S \\
\hline Treatment 2 & 53 & 73 & -8.72 & 29 & S \\
\hline Treatment 3 & 55 & 78 & -11.54 & 29 & S \\
\hline
\end{tabular}

\section{REFERENCES:}

Angela,O.,(2010) The development of Gender Idendtity. https://www.mentalhelp.net/articles/thedevelopment-of-gender-identity/

Beauchemin, J., Hutchins, T.L. \& Patterson, F. (2008) Mindfulness meditation may lessen anxiety, promote social skills and improve academic performance amongst adoles cents with learning difficulties. Complementary Health Practise Review, 13, 34--45.

Bolognini, Plancherel, Bettschart, \& Halfon, 1996; Bolognini, M., Plancherel, B., Bettschart, W., \& Halfon, O. (1996). Self-esteem and mental health in early adolescence: Development and gender differences. Journal of Adolescence, 19, 233-245.

Brown, K. M., McMahon, R. P., Biro, F. M., Crawford, P., Schreiber, G. B., Similo, S. L., Waclawiw, M., \& StriegelMoore, R. (1998). Changes in self-esteem in Black and White girls between the ages of 9 and 24 years: The NHLBI Growth and Health Study. Journal of Adolescent Health, 23, 7-19.

Carver, C. S., \& Connor-Smith, J. (2010). Personality and coping. Annual Review of Psychology, 61, 679-704. doi: 10.1146/ annurev. psych. 093008. 100352.

Chubb, Fertman, \& Ross, 1997 Chubb, N. H., Fertman, C. I., \& Ross, J. L. (1997). Adolescent self-esteem and locus of control: A longitudinal study of gender and age differences. Adolescence, 32, 113-129.

Cronkite, R. C., \& Moos, R. H. (1995). Life context, coping processes, and depression. In E. E. Beckham \& W. R. Leber (Eds.), Handbook of depression (pp. 569-587). New York: Guilford Press.

Cunningham, E. G., Brandon, C. M., \& Frydenberg, E. (2002). Enhancing coping resources in early adolescence through a school-based program teaching optimistic thinking skills. Anxiety, Stress and Coping, 15, 369-381

Durlak, J. A., \& Wells, A. M. (1997). Primary prevention mental health programs for children and adolescents: A meta-analytic review. American Journal of Community Psychology, 25, 115-152.

Frydenberg \& Lewis, 1993a Frydenberg, E, \& Lewis, R. (1993). Adolescent coping: The different ways in which boys and girls cope. Journal of adolescence, 14, 119-133.

Frydenberg, E., \& Lewis, R. (2000). Teaching coping to adolescents: When and to whom? American Educational Research Journal, 37, 727/45

K. Dubat, S. Punia and Rashmi Goyal (2007). A Study of Life Stress and Coping Styles among Adolescent Girls. Journal of Social Science, 14(2): 191- 194. 
Krohne, H. W. (1993/ Vigilance and cognitive avoidance as concepts in coping research. In H. W. Krohne (Ed.), Attention and avoidance (pp. 51-69).

McCallie, M.S., Blum, C.M., \& Hood, C.J. (2006). Progressive Muscle Relaxation. Journal of Human Behavior \& Social Environment, 13, 51-66.Miller 1981

Moos, R. H., \& Schaefer, J. A. (1993). Coping resources and processes: Current concepts and measures. In L. Goldberger \& S. Breznitz. (Eds.), Handbook of stress: Theoretical and clinical aspects (2nd ed., pp. 234-257). New York: Free Press.

Nickel et al (2005) Effect of progressive muscle relaxation in adolescent female bronchial asthma patients: a randomized double-blind, controlled study. J Psychosom Res. Dec; 59(6):393-8.

Nolen-Hoeksema (1994. An interactive model for the emergence of gender differences in depression in adolescence. J. Res. Adolesc. 4:519-34

Ospina MB, Bond K, Karkhaneh M, et al (2007). Meditation practices for health: state of the research. Evidence Report/Technology Assessment;(155):1-263. [PMC free article] [PubMed]

Parlow, L.A., 7 Jones, G.E. (2002). The impact of abbreviated progressive muscle relaxation on salivary cortisol. Biologcal Psychology, 60, 1-16.

Recklitis, C. J., \& Noam, G. G. (1999). Clinical and developmental perspectives on adolescent coping. Child Psychiatry and Human Development, 30, 87-101

Seiffge-Krenke, I., Weidermann, S., Fentner, S., Aegenheister, N., \& Poeblau, M. (2001). Coping with school-related stress and family stress in healthy and clinically referred adolescents. European Psychologist, 6, 123-132.

Skinner, E.A, Edge K, Altman J, Sherwood H. 2003. Searching for the structure of coping: a review and critique of category systems for classifying ways of coping. Psychol. Bull.129:216-69.

How to cite this article: P Rao (2016), Attenuation of Avoidance Coping and Enhancing Approach Coping Strategies of Adolescent Girls, International Journal of Indian Psychology, Volume 3, Issue 3, No. 5, DIP: 18.01.091/20160303 